\title{
CONTABILIZAÇÃO DE TÍTULOS E VALORES MOBILIÁRIOS: UMA COMPARAÇÃO ENTRE AS NORMAS BRASILEIRAS, DO FASB E DO IASB
}

\author{
ACCOUNTING TREATMENT OF DEBT AND EQUITY SECURITIES: \\ A COMPARISON AMONG BRAZILIAN, FASB AND IASB STANDARDS
}

\author{
ALCEU HARUO FUJ \\ Mestre em Ciênciàs Contábeis pela Pontifíicia Universidade Católica de São Paulo \\ E-mail: alceu.haruio@uol.com.br
}

\section{RESUMO}

Em 2001, o Banco Central do Brasil emitiu a Circular 3.068, determinando a utilização do valor de mercado para avaliar os títulos e valores mobiliários. A Circular 3.068/01 determina que os títulos e valores mobiliários devem ser classificados numa das seguintes categorias: negociação, disponíveis para venda e mantidos até o vencimento. Os títulos para negociação e os disponíveis para venda devem ser avaliados e registrados pelo seu valor de mercado e os mantidos até o vencimento devem ser registrados pelo seu custo histórico. O objetivo deste trabalho é estudar a forma de contabilização de títulos adotada no Brasil, especialmente as normas definidas para as instituições financeiras, em comparação com as normas do FASB e IASB. A comparaçã̀o da forma de contabilização de títulos adotada no Brasil (Circular 3.068/01) com os pronunciamentos do FASB (SFAS 115) e IASB (IAS 39) mostrou que, nos aspectos relevantes, as regras estão em harmonia, embora algumas diferenças pequenas tenham sido identificadas.

Palavras-chave: Títulos e valores mobiliários. Contabilização a valor de mercado. Instituições financeiras.

\section{ABSTRACT}

In 2001, the Brazilian Central Bank issued Circular letter 3.068, determining the use of market value to evaluate debt and equity securities. This letter states that debt and equity securities must be classified in one of the following categories: trading, available for sale and held to maturity. The securities for trading and available for sale have to be evaluated and reported by their market value and those held to maturity must be reported by historical cost. The purpose of this work is to study the accounting methods of securities adopted in Brazil, especially those rules stated to financial institutions, in comparison with the statement of FASB and IASB. The comparison of the accounting methods of securities adopted in Brazil (Circular 3.068/01) with the statements of FASB (SFAS 115) and IASB (IAS 39) showed that, in the main aspects, the rules are in harmony, although some minor differences have been identified.

Keywords: Debt and equity securities. Market value accounting. Financial institutions. 


\section{INTRODUÇÃO}

O objetivo deste artigo é examinar a forma de contabilização dos títulos e valores mobiliários adotada no Brasil, especialmente as normas definidas para as instituições financeiras, em comparação com as regras americanas do FASB e internacionais do IASB.

O critério de avaliação e a forma de contabilização dos títulos e valores mobiliários tem sido objeto de muitas discussões, especialmente nos Estados Unidos, por parte dos órgãos reguladores de padrões contábeis (FASB - Financial Accounting Standards Board), entidades de classe dos contadores (AICPA - American Institute of Certified Public Accountants), entidades de supervisão bancária (Federal Reserve), de supervisão do mercado de capitais (SEC - Securities and Exchange Commission), entre outros. No âmbito internacional, o IASB (International Accounting Standards Board), também, emitiu um pronunciamento definindo critérios de avaliação semelhantes aos estabelecidos pelo FASB.

Nos Estados Unidos, a avaliação dos títulos, antes da implementação da contabilização pelo valor justo, era efetuada de diversas formas. Algumas entidades registravam pelo custo histórico, algumas pelo valor de mercado, outras pelo custo histórico ou valor de mercado, dos dois o menor, e, ainda outras, por uma combinação desses métodos para diferentes tipos de títulos.

Essa situação provocou uma discussão intensa sobre a adequação de se utilizar o método do custo como forma de mensuração dos títulos. O método do custo era considerado como um dos principais fatores utilizados para maquiar a insolvência das empresas, especialmente das instituições bancárias, postergando, assim, uma resposta imediata quando uma crise ocorria.

Em artigo no qual examinam a utilização do custo ou mercado, dos dois o menor (LOCOM - Lower of Cost or Market) dentro do contexto da estrutura básica da contabilidade, Foran e Foran (1987, p. 45) criticam a utilização do LOCOM como forma de mensuração de ativos, pois esse método somente fornece uma apresentação do fluxo de caixa adequada e, conseqüentemente, informação útil, quando o valor de mercado for menor que ou igual ao valor de custo do título. Porém, o método será deficiente se o valor de mercado for superior ao de custo, porque custo e não valor de mercado será incluído no ativo total e, na opinião dos autores, o valor de mercado apresenta de forma mais apropriada o fluxo de caixa a ser realizado.

Foran e Foran (1987, p. 45) afirmam, ainda, que a utilização do LOCOM abre uma possibilidade para as empresas manipularem os seus resultados. Uma empresa, que deseje postergar o reconhecimento de receitas, manteria em carteira os títulos com valor de mercado superior ao do custo. Por outro lado, uma empresa que deseje apresentar um resultado melhor, venderia os títulos com valor de mercado superior ao do custo, reconheceria o ganho resultante e, então, após a data do balanço recompraria títulos idênticos ou similares. Dessa forma, o LOCOM ignora a realidade econômica e distorce a tendência dos lucros por não reportar mudanças de valor quando elas ocorrem.

Como conseqüência, passou a se avaliar a contabilização dos títulos pelo seu valor justo, que representaria de forma mais consistente a real situação das empresas, especialmente das instituições financeiras.

O termo valor justo é utilizado, pois muitos ativos não são negociados em mercados líquidos e ativos e, portanto, o valor de mercado não pode ser prontamente determinado. A medida de valor justo representa a avaliação que o mercado faz do risco e do retorno esperado pelos investidores nos investimentos em ativos financeiros. Essa avaliação considera as expectativas relacionadas com o fluxo de caixa futuro que o ativo proporcionará.

O valor justo, conforme Hendricksen e Van Breda (1999, p. 309), refere-se ao capital total sobre o qual os investidores têm o direito de obter um retorno justo. Os autores esclarecem, ainda, que o valor justo não é uma base específica de avaliação que possa ser aplicada de maneira generalizada às demonstrações financeiras.

Os defensores da contabilização a valor justo acreditam que, se comparado ao custo histórico, ele é mais relevante e útil para a tomada de decisão dos investidores, atuais e potenciais, dos credores, e de outros investidores.

Segundo o FASB, as mudanças no valor justo e, conseqüentemente, no retorno de mercado, durante o período em que um título de dívida ou ação é mantido em carteira, fornecem uma referência para avaliar os resultados obtidos pelas decisões dos administradores e o seu sucesso em maximizar os lucros utilizando os recursos econômicos da empresa (FASB, 1993).

As opiniões sobre a efetividade da contabilização a valor justo são controversas. Os profissionais contrários à adoção dessa forma de avaliação argumentam que os resultados podem apresentar uma maior volatilidade, o que pode levar as instituições a alterarem o seu portfolio de investimentos e, conseqüentemente, provocarem uma instabilidade no mercado de títulos.

A utilidade da informação do valor justo também é questionada nos casos em que a instituição tem a intenção de manter o título até o vencimento. Nessa situação, a instituição irá receber o valor nominal do título na data de vencimento e as mudanças no valor de mercado não afetarão os fluxos de caixa futuros, podendo ter pouca relevância para os usuários, a não ser que as mudanças no valor de mercado reflitam uma mudança no risco de pagamento do emissor do título. Se ocorrer uma mudança no risco de pagamento do emissor, ou seja, a probabilidade de inadimplência aumentar, deve-se constituir uma provisão para perdas. Então, a possível vantagem da contabilização a custo histórico é que ele não reflita os efeitos de eventos externos que não tenham influência nos fluxos de caixa futuros.

Os defensores da avaliação pelo custo histórico acreditam que esse é normalmente mais verificável do que o 
valor justo e essa é uma das principais razões por que a comunidade contábil tem relutado em abandoná-lo. Um dos grandes problemas com a mensuração a valor justo é a subjetividade envolvida na mensuração de muitos ativos.

Segundo ludícibus e Martins (2007, p. 17), "A introdução do Valor Justo representa, sem dúvida, significativo avanço nas práticas contábeis. Entretanto, a fim de não provocar reações exacerbadas, seria interessante tornar mais objetiva sua mensuração e introduzi-lo nas demonstrações contábeis em quadros suplementares, ou ainda em notas explicativas, pelo menos até que a prática se consolide".

O FASB acredita que uma estimativa razoável do valor justo possa ser efetuada para todos os títulos de dívida, mesmo que não sejam negociados de forma ativa, através da utilização de técnicas de avaliação alternativas, como, por exemplo, o fluxo de caixa descontado.

Na opinião de Lisboa et al., a Contabilidade deve, acima de tudo, informar. Os autores esclarecem que cada usu- ário da informação tem o seu próprio modelo decisório, cabendo ao mesmo a utilização, ou não, das informações e, nessa ótica, a atitude do FASB é corajosa no sentido de que se afasta do objetivismo do custo histórico ao utilizar o Fair value e procura detalhar ao máximo a movimentação econômica do patrimônio.

Considerando que os investidores necessitam saber a situação da empresa na data das demonstrações contábeis e não no momento em que o ativo foi adquirido, é válida a adoção de normas que caminhem para uma utilização maior do valor justo, pois o valor justo reflete as condições econômicas e de mercado atuais do ativo e, portanto, espera-se que ele tenha um valor preditivo maior do que o custo histórico.

A seguir, são apresentadas as normas de contabilização de títulos e valores mobiliários do FASB, IASB e do Brasil. Posteriormente, destacam-se as principais diferenças entre os normativos.

\section{NORMAS DE CONTABILIZAÇÃO DOS TÍTULOS E VALORES MOBILIÁRIOS}

\subsection{Norte-americanas (SFAS 115 , do FASB)}

O pronunciamento do FASB, em vigor, que aborda a avaliação e contabilização dos títulos e valores mobiliários é o SFAS 115 - Accounting for Certain Investments in Debt and Equity Securities, emitido em maio de 1993. O pronunciamento expande a utilização do valor justo (fair value) para esses títulos; porém, mantém a utilização do custo histórico para investimentos em títulos de dívida que a empresa tenha a intenção e habilidade de manter até o vencimento.

\subsection{Escopo}

O SFAS 115 aplica-se aos investimentos em ações que tenham valor justo, prontamente determináveis e para todos os investimentos em títulos de dívida. Esse pronunciamento não se aplica aos investimentos em ações contabilizadas pelo método da equivalência patrimonial ou investimentos de subsidiárias consolidadas. Com relação às empresas, todas estão obrigadas a seguir o pronunciamento, exceto as organizações sem fins lucrativos e as empresas cuja prática contábil específica inclui a contabilização de, substancialmente, todos os investimentos em títulos e valores mobiliários a valor de mercado ou valor justo, como, por exemplo, corretoras e distribuidoras de títulos e valores mobiliários, planos de pensão de benefícios definidos e companhias de investimento.

\subsection{Avaliação e contabilização}

O pronunciamento SFAS 115 , estabelece que os títulos devem ser classificados em três categorias e contabilizados da seguinte forma:

a) mantidos até o vencimento: títulos de dívida que a empresa tenha a habilidade e intenção de manter até o vencimento, devendo ser registrados ao custo amortizado;

b) negociação: títulos de dívida e patrimoniais comprados e vendidos para realizar lucros de curto prazo, devendo ser registrados a valor justo. Ganhos ou perdas não realizados devem ser incluídos na demonstração de resultados e

c) disponível para venda: títulos de dívida e patrimoniais que não foram designados para uma das categorias anteriores. São títulos que deverão ser mantidos em carteira por um período de tempo não determinado, por exemplo, aqueles que a entidade poderá vender para atender necessidades de liquidez ou como parte do gerenciamento de risco da entidade. Esses títulos devem, também, ser registrados pelo valor justo, porém, os ganhos e perdas não realizados são registrados como outros resultados abrangentes.

A destacar que o pronunciamento não prevê a classificação de ações na categoria de mantidos até o vencimento. Isso ocorre, basicamente, pelo fato de as ações não possuírem uma data de vencimento definida.

Posteriormente, o SFAS 159 The Fair Value Option for Financial Assets and Financial Liabilities permitiu que os títulos que estavam em carteira e classificados em mantidos até o vencimento ou disponível para venda, na data de adoção desse pronunciamento, fossem elegíveis à opção de valor justo, sendo que os ganhos e perdas não realizados deviam ser incluídos como ajuste nos lucros acumulados. Os títulos que forem nomeados a valor justo deviam ser transferidos para a categoria de negociação.

Wampler e Phillips (1994, p. 47) destacam que o SFAS 115 não soluciona o problema da manipulação dos resul- 
tados e, de certo modo, pode até facilitar a administração do resultado. Por exemplo, a reclassificação de um título para a categoria de negociação exige o reconhecimento no resultado de qualquer ganho ou perda não realizado. Enquanto as regras anteriores exigiam a venda do título para manipular o resultado, a nova regra cria o potencial para administrar o resultado baseado somente na mudança da intenção declarada de venda.

O problema básico é analisar qual método reflete a condição atual de uma entidade de forma mais apropriada. As normas contábeis não deveriam ser utilizadas para suavizar os resultados. Se a estratégia de investimento e financiamento de uma empresa é particularmente sensível às mudanças nas taxas de juros, as suas demonstrações contábeis deveriam representar o resultado dessa estratégia de forma verdadeira, mesmo que os resultados apresentassem maior volatilidade. A contabilização a valor justo atinge esse objetivo ao reconhecer os ganhos e perdas quando eles ocorrem, ao invés de quando a administração decide reconhecê-los (WAMPLER; PHILLIPS, 1994, p. 47).

Jordan et al. (1997/1998) pesquisaram o gerenciamento de resultados sob o SFAS 115 . O reconhecimento dos ganhos e perdas não realizados com os títulos da categoria de disponíveis para venda no patrimônio líquido, sem transitar pelo resultado, cria oportunidades para ganhos com negociação e gerenciamento de resultados, isto é, para atingir um nível desejado de lucro, a administração pode vender os títulos de forma seletiva de forma que os ganhos e perdas não realizados afetem o resultado. $O$ estudo forneceu fortes evidências de que ganhos com negociação ocorrem sob o SFAS 115, pelo menos com relação às companhias de seguro. Segundo os autores, as implicações das descobertas são importantes por dois motivos. Primeiro, os usuários das demonstrações financeiras devem estar cientes de que ganhos com negociação e gerenciamento de resultados existem sob o SFAS 115. Ganhos com negociação para atingir níveis de resultado desejados não necessariamente implicam em comportamento antiético dos administradores. Porém, ao avaliar a saúde financeira de uma entidade, os usuários precisam estar cientes da presença de ganhos com negociação. Segundo, as descobertas sugerem que as decisões dos administradores são afetadas, pelo menos em parte, pelos padrões contábeis. Os pronunciamentos do FASB não têm a intenção de afetar as decisões operacionais e não devem ser utilizados para moldar a condição financeira da companhia. Isso não obstante, aparentemente, essas duas situações estão ocorrendo sob o SFAS 115. Modificar o SFAS 115 no sentido de exigir que ganhos e perdas não realizados sejam reconhecidos no resultado, pode, efetivamente, eliminar o potencial para ganhos com negociação, mas, ao fazê-lo, poderá aumentar de forma significativa a volatilidade dos resultados de ano para ano, pelo fato de o lucro flutuar com base nas mudanças das taxas de juros.

Apesar do problema de manipulação dos resultados não ser resolvido, o SFAS 115 representa uma evolução na contabilização dos títulos, por eliminar a disparidade de contabilização existente entre as indústrias e por eliminar a falta de imparcialidade do método do custo ou mercado, dos dois o menor. O método do custo ou mercado, dos dois o menor, é imparcial pois utiliza o valor de mercado somente quando esse for inferior ao valor de custo.

Wampler e Phillips (1994, p. 49) acreditam que a utilização da contabilização a valor justo para todos os títulos de dívida não só seria mais consistente, como iria simplificar a contabilização dos títulos, ao eliminar muitas complexidades que permanecem sob o SFAS 115 - por exemplo, avaliar a intenção da administração ou decidir quando um declínio no valor é "outro que não temporário". Embora alguns problemas de contabilização adicionais possam surgir, as vantagens da contabilização a valor justo para títulos - particularmente em termos de maior relevância da informação - supera as desvantagens. Segundo os autores, embora o SFAS 115 seja um passo na direção certa, a adoção completa da abordagem de valor justo para títulos irá resultar em demonstrações contábeis que refletem a realidade econômica da posição financeira da empresa de forma mais apropriada.

O FASB concluiu que os preços cotados a mercado, quando disponíveis, proporcionam a mais confiável medida de valor justo, pelo fato de serem fáceis de se obter e serem confiáveis e verificáveis. Para os títulos de dívida que não são negociados regularmente, uma estimativa razoável pode ser obtida utilizando-se técnicas de determinação de preço, tais como: análise do fluxo de caixa descontado, matriz de preços, modelos de determinação de preços de opções e análise fundamentalista.

Para o FASB, o custo amortizado é a forma de mensuração relevante para os títulos mantidos até o vencimento, pelo fato de que qualquer ganho ou perda intermediária será revertido no vencimento do título.

O pronunciamento prevê algumas situações que podem levar a empresa a mudar sua intenção de manter certos títulos até o vencimento, sem que seja questionada, no futuro, sua intenção de manter os demais títulos até o vencimento. Portanto, a venda ou transferência de um título mantido até o vencimento, em função de uma das seguintes mudanças, não será considerada inconsistente com a classificação original:

a) evidência de uma deterioração significativa no risco de crédito do emissor do título.

b) alteração tributária que elimine ou reduza a isenção sobre os juros recebidos do título de dívida.

c) ocorrência de uma alienação ou combinação de negócios que torne imprescindível a venda ou transferência de títulos mantidos até o vencimento para manter a posição de risco de taxa de juros ou a política de risco de crédito da empresa.

d) mudança nas exigências regulamentares que modifiquem de forma significativa a composição dos investimentos permitidos ou o nível máximo de investimentos em certos tipos de títulos, obrigando, portanto, a empresa a se desfazer do título mantido até o vencimento. 
e) aumento significativo, por parte dos reguladores, de exigência de capital que torne necessária a diminuição do porte da instituição (downsize), através da venda de títulos mantidos até o vencimento.

f) aumento significativo na ponderação do risco de títulos de dívida, utilizada no cálculo de exigência de capital.

Adicionalmente às mudanças citadas, outros eventos que sejam isolados, não recorrentes e não usuais, que não podiam ser razoavelmente antecipados, podem levar a empresa a vender ou transferir os títulos mantidos até o vencimento, sem que seja questionada, no futuro, a sua intenção de manter os demais títulos até o vencimento.

O pronunciamento permite, ainda, a venda de títulos de dívida mantidos até o vencimento em duas situações: (a) quando isso ocorrer em data próxima ao vencimento (por exemplo, três meses), de forma que o risco de taxa de juros é substancialmente eliminado, na determinação do preço do título e (b) quando a venda do título ocorrer após a empresa ter recebido parte substancial (pelo menos 85\%) do principal, seja em função de pagamentos antecipados ou pagamentos programados.

O FASB determinou que mudanças nas taxas de juros, necessidades de liquidez, mudanças nas disponibilidades e nos juros de investimentos alternativos, mudanças nos recursos disponíveis e mudanças no risco cambial, não são motivos para que a empresa venda os títulos mantidos até o vencimento.

O SFAS 115 estabelece que os ganhos e perdas não realizados de títulos para negociação devem ser incluídos na demonstração de resultados. Já para os títulos classificados como disponíveis para vendas, o SFAS 115 estabeleceu, inicialmente, que os ganhos e perdas não realizados deveriam ser excluídos da demonstração de resultados e incluídos em um componente separado do patrimônio líquido, até que fossem realizados. Posteriormente, o SFAS 130 - Reporting Comprehensive Income alterou esse parágrafo, determinando que os ganhos e perdas não realizados devem ser reportados como outros resultados abrangentes. Assim, os ganhos e perdas não realizados com os títulos da categoria de disponíveis para venda, muito embora ainda sejam registrados no patrimônio líquido em uma conta de resultados abrangentes, também devem ser apresentados na demonstração do resultado abrangente, relatório a ser elaborado e publicado junto com os demais relatórios existentes.

O FASB decidiu excluir da demonstração de resultados, os ganhos e perdas não realizados dos títulos da categoria de disponíveis para venda, em função de preocupações com a potencial volatilidade nos resultados, em conseqüência da utilização do valor justo para alguns ativos e nenhum passivo.

O pronunciamento SFAS 115, ao abordar as informações antecedentes (background information), relata que muitos respondentes, especialmente bancos e companhias de seguro, comentaram que a abordagem do pronuncia- mento não era correta por aplicar a utilização do valor justo somente para alguns ativos financeiros e nenhum passivo. Os bancos e as companhias de seguro gerenciam o risco de taxa de juros através da composição de uma carteira de ativos financeiros coordenada com passivos financeiros. Essas instituições apontaram que se o FASB exige que os títulos sejam avaliados a valor justo, ele também deveria exigir (ou pelo menos permitir) que as empresas reportassem os passivos associados a esses ativos a valor justo, para evitar uma volatilidade atípica nas demonstrações contábeis.

Um problema potencial surge se a contabilização a valor justo é utilizada para mensurar somente alguns ativos e passivos, enquanto outros continuam a ser mensurados com base no custo histórico. A aplicação da contabilização a valor justo a uma parte seletiva do balanço patrimonial pode trazer uma demonstração incompleta e distorcida da posição atual da empresa. Entretanto, a contabilização a valor justo de forma abrangente apresenta uma dificuldade pois o valor justo de muitos ativos e passivos não pode ser estimado (WAMPLER; PHILLIPS, 1994, p. 47).

Wampler e Phillips (1994, p. 47) defendem que, embora o uso seletivo de valores de mercado possa resultar em um balanço patrimonial distorcido, não há razão para acreditar que o balanço patrimonial inteiramente baseado no custo histórico seja menos distorcido. Incorporar o valor justo no balanço patrimonial, quando possível, fará com que ele seja menos incorreto.

O FASB defende que uma volatilidade atípica, também, possa ocorrer com a utilização do custo histórico quando os títulos são vendidos de forma seletiva e ganhos e perdas são reconhecidos. Essa volatilidade pode ser mais aceita por alguns pelo fato de a administração poder controlála através da decisão de quais títulos e quando vender. Adicionalmente, o FASB acredita que seria aconselhável permitir que certos passivos relacionados a ativos fossem reportados a valor justo, se fosse exigido que todos os investimentos em títulos sejam reportados a valor justo. Porém, o FASB não conseguiu identificar e os respondentes não propuseram, uma forma de abordar a contabilização dos passivos a valor justo que seja aceitável.

Tendo em vista que muitas empresas administram o risco de taxa de juros de forma global, para todos os ativos e passivos financeiros, o FASB encontrou dificuldades em identificar quais passivos deveriam ser considerados como relacionados com os títulos de dívida contabilizados a valor justo. Além disso, o FASB afirma que o pronunciamento não expande de forma abrangente a utilização do valor justo e práticas existentes reconheciam a redução do valor justo para os títulos mantidos para venda (através do método LOCOM) sem considerar alterações no valor de qualquer passivo.

Para os títulos classificados nas categorias de disponível para venda e mantidos até o vencimento, em que haja um declínio no valor de mercado, outro que não temporário, deve-se efetuar um ajuste a valor justo, com as perdas incluídas na demonstração de resultados. O SEC definiu 
que, outro que não temporário, não significa permanente, ou seja, o reconhecimento da perda deve ocorrer quando for provável que o investidor não será capaz de recuperar o valor registrado do investimento. Eventuais recuperações no valor justo desses títulos não podem ser reconhecidas.

Em 2007, o SFAS 159 The Fair Value Option for Financial Assets and Financial Liabilities expandiu a utilização do valor justo ao permitir que ativos e passivos financeiros sejam designados para avaliação a valor justo. O objetivo do pronunciamento foi melhorar as demonstrações financeiras ao permitir que as entidades reduzam a volatilidade nos resultados, decorrentes da mensuração diferenciada de ativos e passivos financeiros que sejam relacionados. Com o pronunciamento, o FASB espera que haja uma utilização maior do valor justo, que é consistente com os objetivos de longo prazo do órgão.

Com a emissão do SFAS 159 o FASB solucionou parcialmente a distorção decorrente da contabilização a valor justo de uma parte seletiva do balanço patrimonial, ao permitir que ativos e passivos financeiros sejam designados para avaliação a valor justo. Porém, a aplicação da opção de avaliação a valor justo é irrevogável, ou seja, uma vez que o instrumento financeiro seja designado a valor justo, deverá sempre ser avaliado dessa forma.

\subsection{Transferência entre categorias}

As transferências de títulos entre as categorias devem ser efetuadas pelo valor justo. Os ganhos e perdas não realizados de títulos devem ser contabilizados da seguinte forma:

a) para os títulos transferidos para a categoria de negociação, a parcela de ganhos ou perdas não realizados que não tenha sido previamente reconhecida no resultado, deve ser reconhecida imediatamente. Esse tratamento segue o procedimento estabelecido para o reconhecimento dos ganhos/perdas na demonstração de resultados para os títulos da categoria de negociação. Porém, para os títulos retirados da categoria de negociação, os ganhos e perdas não realizados, que foram previamente reconhecidos no resultado, não podem ser revertidos.

b) para os títulos transferidos da categoria mantidos até o vencimento para a categoria de disponíveis para venda, os ganhos ou perdas não realizados devem ser reportados em outros resultados abrangentes. Para os títulos transferidos da categoria dispo- nível para venda para mantidos até o vencimento, os ganhos ou perdas não realizados devem continuar a ser reportados num componente separado do patrimônio líquido, devendo ser amortizados durante o prazo remanescente do título, até o seu vencimento.

O FASB ressalta que as retiradas da categoria de mantidos até o vencimento devem ser raras e dada a natureza dos títulos para negociação, transferências para e dessa categoria também devem ser raras. A expectativa é de que os títulos para negociação sejam vendidos e não reclassificados para outra categoria.

$\mathrm{Na}$ aquisição do título, a empresa deve determinar a classificação em uma das três categorias: mantidos até o vencimento, negociação e disponível para venda. A cada data de balanço, a conveniência da classificação deve ser reavaliada.

\subsection{Exigências de divulgação}

Para os títulos classificados em disponíveis para venda devem ser divulgados o valor justo, os ganhos e perdas totais registrados em outros resultados abrangentes, segregados por tipo de título. Para os títulos classificados em mantidos até o vencimento devem ser divulgados o valor justo e os ganhos e perdas brutos não reconhecidos, segregados por tipo de título.

Para os títulos classificados em disponíveis para venda e mantidos até o vencimento, deve ser divulgada, separadamente, informação sobre o prazo de vencimento dos títulos. Os prazos de vencimento podem ser agrupados em períodos, desde que apresentem pelo menos quatro grupos de vencimento, sendo: (a) um ano, (b) de um a cinco anos, (c) de 5 a 10 anos e (d) mais de 10 anos.

Além disso, o FASB exige a divulgação de outras informações, tais como o lucro na venda de títulos da categoria disponíveis para venda e os ganhos/perdas realizadas brutas que tenham sido incluídas na demonstração de resultados; os ganhos/perdas brutas incluídas no resultado decorrentes de transferências de títulos da categoria de disponível para venda para a de negociação; e para qualquer venda ou transferência da categoria de mantidos até o vencimento, o valor contábil líquido do título vendido ou transferido, o respectivo ganho/perda realizada ou não realizada e as circunstâncias que levaram a empresa a vender ou transferir o título.

\section{NORMAS INTERNACIONAIS (IAS 39, DO IASB)}

O IAS 39 Financial Instruments: Recognition and Measurement tem o objetivo de estabelecer princípios para o reconhecimento e mensuração de ativos e passivos financeiros e alguns contratos de compra e venda de itens não financeiros. Dessa forma, o IAS 39 apresenta-se como um documento abrangente, contemplando a contabilização dos ativos e passivos financeiros, dos instrumentos financeiros derivativos e da contabilização do hedge. Nos Estados Unidos, o FASB aborda esses assuntos em pronunciamentos separados, incluindo o SFAS 114 - Accounting by Creditors for Impairment of a Loan, de maio de 1993; SFAS 115 - Accounting for Certain Investments in Debt and Equity Securities, de maio de 1993 e SFAS 133 - Accounting for Derivative Instruments and Hedging Activities, de junho de 1998. 
O IAS 39 foi objeto de inúmeras críticas, em especial de representantes da indústria bancária. O Comitê da Basiléia (Basel Committee on Bank Supervision) elaborou um relatório contendo uma revisão das Normas Internacionais de Contabilidade. Para o Comitê da Basiléia (2000, p. 14), sob o IAS 39, a maioria dos passivos financeiros serão reportados pelo custo. Reportar a maioria dos passivos pelo custo e introduzir uma maior contabilização a valor justo somente do lado do ativo, irá, provavelmente, aumentar o risco de volatilidade nos lucros e no patrimônio liquido, que pode não refletir as práticas de gerenciamento de risco dos bancos, por exemplo, no caso de posições ativas e passivas administradas em conjunto.

Adicionalmente, o Comitê ressalta que surgem dúvidas sobre a mensuração a valor justo, particularmente com ativos (e passivos) não negociados de forma ativa, que anteriormente eram mantidos pelo custo. Na ausência de mercados ativos, existirão dificuldades de se obterem ou calcularem valores justos confiáveis e, mesmo quando valores justos aparentemente sejam estimáveis, em alguns países a confiabilidade disso será duvidosa.

\subsection{Escopo}

A norma aplica-se a todas as entidades e a todos os tipos de instrumentos financeiros, exceto: (a) interesses em subsidiárias, coligadas e joint ventures que são contabilizados segundo o IAS 27 Consolidated and Separate Financial Statements, IAS 28 Investments in Associates ou IAS 31 Interests in Joint Ventures; (b) direitos e obrigações de contratos de leasing, aos quais se aplica o IAS 17 Leases; (c) direitos e obrigações de empregados decorrentes de planos de benefícios, aos quais se aplica o IAS $19 \mathrm{Em}$ ployee Benefits; (d) direitos e obrigações decorrentes de contratos de seguro; (e) instrumentos financeiros que estejam dentro da definição de patrimônio próprio, segundo o IAS 32; (e) contratos de eventos contingentes em uma combinação de negócios; (f) contratos que exijam pagamentos baseados em condições climáticas, geológicas e outras variáveis físicas.

\subsection{Avaliação e contabilização}

As exigências de mensuração do IAS 39 são, em grande parte, similares às exigências do FASB. Porém, relativamente aos ativos financeiros a contabilização definida pela norma do IASB adota alguns termos e procedimentos diferentes da norma norte-americana (SFAS 115).

O IAS 39 estabelece que os instrumentos financeiros devem ser classificados em uma das seguintes categorias:

a) ativos ou passivos financeiros a valor justo, por via dos resultados;

b) investimentos mantidos até o vencimento;

c) empréstimos e valores a receber $e$

d) ativos financeiros disponíveis para venda.

Essas categorias são utilizadas para definir como um ativo ou passivo financeiro é reconhecido e mensurado nas demonstrações contábeis.
Os ativos ou passivos financeiros a valor justo, por via dos resultados, possuem duas subcategorias:

a) negociação: um ativo ou passivo financeiro é classificado como detido para negociação se for adquirido ou incorrido principalmente para a venda e recompra num prazo curto ou se fizerem parte de um portfolio gerenciado em conjunto, para o qual existe um modelo real e recente de obtenção de lucros de curto prazo. Negociação, geralmente, reflete a compra/venda ativa e freqüente e os instrumentos financeiros mantidos para negociação, em geral, são utilizados com o objetivo de gerar lucro em função da flutuação de curto prazo, nos preços ou nas margens do negociador.

b) designados: qualquer ativo ou passivo financeiro que seja designado, quando do reconhecimento inicial, para ser mensurado a valor justo, por via dos resultados. Em 2005, o IASB limitou a utilização dessa opção para os instrumentos financeiros que atendam às seguintes condições: a) a designação da opção de valor justo elimina ou reduz de forma significativa uma contabilização desbalanceada (accounting mismatch); b) um grupo de ativos financeiros, passivos financeiros ou os dois são gerenciados e a sua performance é avaliada com base no valor justo, estando em acordo com um gerenciamento de risco documentado ou estratégia de investimento e c) um instrumento contém um derivativo embutido que satisfaça certas condições.

A grande vantagem de se designar um ativo ou passivo financeiro a valor justo, por via dos resultados é a possibilidade de a empresa reduzir a volatilidade dos resultados, contabilizando a valor justo os ativos e passivos financeiros, que sejam administrados de forma conjunta. Porém, existe a desvantagem de que a designação é permanente. Portanto, se um item ativo ou passivo deixar de existir, a empresa deve manter a contabilização a valor justo do outro item, com os ganhos e perdas não realizados reconhecidos no resultado.

Os ativos financeiros a valor justo, por via dos resultados devem ser mensurados a valor justo, devendo os ganhos e perdas não realizados serem reconhecidos no resultado do período. Para os investimentos em ações que não tenham um preço de mercado cotado em um mercado ativo e para o qual um valor justo não possa ser mensurado de forma confiável, a norma abre uma exceção, determinando que esses devem ser mensurados pelo custo amortizado.

Os investimentos mantidos até o vencimento são ativos financeiros não derivativos com pagamentos fixos ou determinados e prazo de vencimento definido que a entidade tenha a intenção positiva e habilidade de manter até o vencimento. Essa categoria é mensurada pelo custo amortizado.

Uma entidade fica proibida de utilizar a classificação de mantidos até o vencimento se a entidade tiver, durante o ano corrente ou durante os dois anos precedentes, vendido 
ou reclassificado mais do que um montante insignificante de ativos classificados como mantidos até o vencimento (mais do que insignificante em relação ao montante total dos investimentos mantidos até o vencimento).

A norma permite a venda ou reclassificação de ativos mantidos até o vencimento em algumas situações específicas, sem que seja questionada a intenção de manter até o vencimento. Isso ocorre quando a venda for efetuada próxima à data de vencimento ou da opção de compra (menos de três meses), de forma que as alterações na taxa de juros de mercado não tenham um efeito significativo no valor justo do ativo; quando a venda ocorrer após a entidade ter recebido, substancialmente, todo o capital principal ou quando a venda for decorrente de um evento isolado que esteja fora do controle da entidade, seja não recorrente e não pudesse ser razoavelmente previsto pela entidade.

Além disso, de forma similar ao SFAS 115, o pronunciamento prevê algumas situações de venda antes do vencimento, sem que seja questionada, no futuro, a intenção de manter os demais títulos até o vencimento. Por exemplo, a entidade não será questionada se a venda for atribuível a uma deterioração significativa no risco de crédito do emissor do título ou devido a uma alteração tributária que elimine ou reduza a isenção sobre os juros recebidos do título de dívida.

Adicionalmente, o IAS 39 estabelece que uma entidade não tem a intenção positiva de manter um investimento até o vencimento se: (a) ela pretende manter o ativo financeiro por um período de tempo não definido; (b) ela pretende vender o ativo financeiro em decorrência de mudanças nas taxas de juros ou risco de mercado, de necessidade de liquidez, de mudanças nas disponibilidades e nos juros de investimentos alternativos, de mudanças nas fontes de recursos e de mudanças no risco da taxa de câmbio e (c) o emissor tem o direito de liquidar o ativo financeiro por um montante significativamente inferior ao custo amortizado.

Os empréstimos e valores a receber são ativos financeiros não derivativos com pagamentos fixos ou determinados que não sejam cotados em um mercado ativo. Os ativos dessa categoria devem ser mensurados pelo custo amortizado.

Os empréstimos e valores a receber em que o credor possa não recuperar substancialmente a totalidade do investimento inicial, devem ser classificados como disponíveis para venda.

Os ativos financeiros disponíveis para venda são aqueles designados como disponíveis para venda ou que não sejam classificados numa das categorias anteriores. Os ativos dessa categoria devem ser avaliados a valor justo, com os ganhos e perdas não realizados reconhecidos diretamente no patrimônio líquido.

O valor justo, conforme definido na norma, é o montante pelo qual um ativo poderia ser trocado entre partes conhecedoras e interessadas, numa transação em que não exista relacionamento entre elas. O IASB considera que a existência de cotações de preço publicadas num mercado ativo é a melhor evidência de valor justo e quando existirem devem ser utilizadas para mensurar o ativo financeiro. Se um mercado ativo não existe, o valor justo deve ser estabelecido através de técnicas de avaliação, como: análise de fluxo de caixa descontado e referências de valor justo de outros instrumentos semelhantes.

A norma estabelece que as empresas devem avaliar, a cada data de balanço, se existe qualquer evidência de que um ativo financeiro ou um grupo de ativos financeiros perdeu valor. A perda de valor de um ativo pode ser decorrente de uma dificuldade financeira significativa do emissor; uma quebra de contrato, tal como o descumprimento nos pagamentos dos juros ou principal; uma grande probabilidade de falência ou o desaparecimento de um mercado ativo para esse ativo financeiro, decorrente de dificuldades financeiras.

Para os ativos classificados nas categorias de mantidos até o vencimento e disponíveis para venda, se houver evidência de que houve perda de valor, o montante da perda deve ser mensurado e reconhecido no resultado. Em períodos subseqüentes, a reversão de perdas reconhecidas dos ativos mantidos até o vencimento é permitida até o montante que seria registrado pelo custo amortizado, se não tivesse sido registrada a perda. As reversões da categoria de disponíveis para venda são permitidas somente para os títulos de dívida, sendo proibidas para as ações.

\subsection{Transferência entre categorias}

A transferência para e da categoria ativos financeiros a valor justo, por via dos resultados não é permitida, enquanto o ativo for mantido em carteira. Em função da norma permitir que uma entidade designe qualquer ativo ou passivo financeiro, no reconhecimento inicial, para ser mensurado a valor justo, o IASB proibiu a reclassificação desses títulos, com o intuito de impor uma disciplina na utilização dessa categoria.

Se, em decorrência de uma mudança na intenção ou habilidade, não for mais apropriado classificar um investimento como mantido até o vencimento, ele deve ser reclassificado para disponível para venda e mensurado a valor justo.

As transferências da categoria de mantidos até o vencimento resultantes de uma mudança na intenção ou habilidade são consideradas como vendas e, portanto, salvo circunstâncias excepcionais, quando isso ocorrer, todos os demais títulos mantidos até o vencimento devem ser reclassificados para a categoria de disponível para venda e mensurados a valor justo.

Se, em decorrência de mudança na intenção ou habilidade, ou nas raras circunstâncias em que uma medida de valor justo não esteja mais disponível, ou porque os dois anos de proibição de classificar ativos como mantidos até o vencimento tenha expirado, se tornar apropriado registrar um ativo financeiro pelo custo ou custo amortizado em vez do valor justo, o valor justo do ativo registrado nessa data torna-se o novo custo ou custo amortizado, conforme aplicável. 


\subsection{Exigências de divulgação}

As exigências de divulgação que existiam no IAS 39, edição revisada de 2000, foram todas transferidas para o IAS 32 - Financial Instruments: Disclosure and Presentation. Dessa forma, a edição atual do IAS 32 (revisada de 2003) inclui todas as exigências de divulgação relativas aos instrumentos financeiros.

O objetivo das exigências de divulgação do IAS 32 é fornecer informações que permitam avaliar a importância dos instrumentos financeiros para a posição financeira, a performance e o fluxo de caixa da entidade. O pronunciamento exige várias divulgações relacionadas aos instrumentos financeiros, incluindo informações sobre os seus valores justos.

As exigências de divulgação relacionadas com os títulos e valores mobiliários estão descritas a seguir:

a) termos, condições e políticas contábeis: para cada classe de ativo financeiro a entidade deverá divulgar: (a) informações sobre a natureza do ativo financeiro, incluindo os termos e condições que possam afetar o montante, o prazo e a certeza dos fluxos de caixa futuros e (b) as políticas contábeis adotadas, incluindo os critérios de reconhecimento e as bases de mensuração aplicadas.

b) risco de taxa de juros: para cada classe de ativo financeiro a entidade deverá divulgar informações sobre a exposição ao risco de taxa de juros, incluindo as datas de repactuação ou vencimento, o que ocorrer primeiro, e a taxa de juros efetiva, quando aplicável.

c) risco de crédito: para cada classe de ativo financeiro a entidade deverá divulgar informações sobre a exposição ao risco de crédito, incluindo o montante que melhor represente o máximo de exposição ao risco de crédito e as concentrações relevantes de risco de crédito. d) valor justo: para cada classe de ativo financeiro a entidade deverá divulgar o valor justo do ativo. Entretanto, se o investimento for em ações não cotadas em mercado, contabilizadas pelo custo, em função do valor justo não ser mensurável de forma confiável, esse fato deve ser divulgado juntamente com uma descrição do instrumento financeiro, o montante contabilizado, uma explicação do porquê o valor justo não pode ser mensurado de forma confiável e, se possível, um intervalo de estimação, dentro do qual o valor justo possa estar contido.

e) ativos financeiros contabilizados a valor justo através dos resultados: a entidade deve divulgar o montante dos ativos financeiros classificados como negociação e dos que foram inicialmente designados pela entidade como a valor justo, por via dos resultados.

f) reclassificação: se uma entidade reclassificou um ativo financeiro como mensurado pelo custo ou custo amortizado ao invés de pelo valor justo, ela deve divulgar a razão dessa reclassificação.

g) demonstração de resultados e patrimônio: a entidade deve divulgar os itens relevantes de receita, despesa e ganhos e perdas resultantes de ativos financeiros, quer incluídos nos resultados quer como um componente separado do patrimônio líquido. Para os ativos classificados como disponíveis para venda, deve ser divulgado, ainda, o montante de qualquer ganho ou perda reconhecido diretamente no patrimônio líquido e o montante que foi removido do patrimônio e reconhecido no resultado durante o período.

h) prejuízo por perda de valor: a entidade deve divulgar a natureza e o montante de qualquer prejuízo por perda de valor de ativo financeiro, reconhecido nos resultados.

\section{NORMAS CONTÁBEIS BRASILEIRAS (CIRCULAR 3.068/01, DO BANCO CENTRAL)}

A Circular 3.068/01 adota procedimentos semelhantes aos emanados do FASB e IASB. O artigo $1^{\circ}$ estabelece que os títulos e valores mobiliários devem ser registrados pelo valor efetivamente pago, inclusive corretagens e emolumentos, e classificados em três categorias, de forma semeIhante ao estabelecido pelo FASB: negociação, mantidos até o vencimento e disponível para a venda.

Os critérios estabelecidos pela Circular 3.068/01 eram divergentes com as regras estabelecidas pela Lei 6.404/76 (Lei das S/As), que estabelecia como critério de avaliação o custo de aquisição ou valor de mercado, se este for menor. Porém, a Lei 11.638/07, de 28 de dezembro de 2007, alterou esse dispositivo, ao estabelecer que as aplicações em instrumentos financeiros sejam avaliadas pelo seu valor de mercado ou equivalente, quando se tratar de aplicações destinadas à negociação ou disponíveis para venda; e pelo custo de aquisição nas demais aplicações.

Assim, a partir de janeiro de 2008, quando entrou em vigor a Lei 11.638/07, as regras estabelecidas para as So- ciedades Anônimas ficaram semelhantes às das instituições financeiras.

\subsection{Escopo}

A Circular 3.068/01 aplica-se às instituições financeiras e demais entidades autorizadas a funcionar pelo Banco Central do Brasil, exceto cooperativas de crédito, agências de fomento e sociedades de crédito ao microempreendedor.

\subsection{Avaliação e contabilização}

O Quadro 10 apresenta um resumo das categorias e respectivas regras de contabilização definidas pela Circular 3.068/01.

De acordo com as regras estabelecidas na Circular, a contabilização dos títulos e valores mobiliários é fortemente baseada na intenção da instituição. Assim, dependendo do critério que a instituição utiliza para classificar os títulos e a conseqüente contabilização do ajuste a valor de mercado, pode-se obter diferentes resultados. O Qua- 


\begin{tabular}{|l|l|l|l|}
\multicolumn{1}{|c|}{ Categorias } & \multicolumn{1}{c|}{ Características } & \multicolumn{1}{c|}{ Avaliação } & \multicolumn{1}{c|}{ Contrapartida do ajuste } \\
\hline I- títulos para negociação & Negociação ativa e freqüente & Valor de mercado & Conta de resultado \\
\hline II - títulos disponíveis para venda & Não enquadrados nas categorias I e III & Valor de mercado & Conta destacada do PL \\
\hline $\begin{array}{l}\text { III - títulos mantidos até o } \\
\text { vencimento }\end{array}$ & $\begin{array}{l}\text { Intenção e capacidade financeira de } \\
\text { manter até o vencimento }\end{array}$ & Custo de aquisição & Não têm ajuste \\
\hline
\end{tabular}

Quadro 1 || Classificação dos Títulos e Valores Mobiliários

dro 20 apresenta os principais impactos decorrentes da classificação adotada.

A classificação dos títulos na categoria de negociação expõe a instituição a uma volatilidade maior nos resultados, decorrente de variações no valor de mercado, pois todos os ganhos e perdas são reconhecidos no resultado. Porém, para os títulos cujo valor de mercado esteja superior ao de custo, ou seja, com ganhos não realizados, a utilização da categoria de negociação permite melhorar o lucro líquido do período.

Para os títulos classificados em disponíveis para venda, pode ocorrer uma maior volatilidade do patrimônio líquido, pois os ajustes decorrentes de variações no valor de mercado serão incluídos em um componente separado do patrimônio líquido.

A classificação dos títulos na categoria de mantidos até o vencimento evita o impacto dos ajustes a valor de mercado na demonstração de resultados ou no patrimônio líquido, pois esses títulos ficam registrados pelo custo histórico. Porém, os títulos mantidos até o vencimento não poderão ser utilizados, no futuro, para atender uma eventual necessidade de liquidez da instituição. Se um título dessa categoria for vendido, a classificação de todos os demais títulos mantidos até o vencimento pode ser questionada e, conseqüentemente, ser exigida a reclassificação de todos os títulos para a categoria de disponíveis para venda, com os respectivos ajustes a valor de mercado sendo reconhecidos no patrimônio líquido.

A norma do Banco Central utilizou o termo "valor de mercado", ao invés do termo "valor justo" utilizado pelas normas norte-americanas e internacionais. A norma estabelece que pode ser utilizado como parâmetro para definição do valor de mercado:
I o preço médio de negociação no dia da apuração ou, quando não disponível, o preço médio de negociação no dia útil anterior;

II o valor líquido provável de realização obtido mediante adoção de técnica ou modelo de precificação;

III o preço de instrumento financeiro semelhante, levando em consideração, no mínimo, os prazos de pagamento e vencimento, o risco de crédito e a moeda ou indexador.

Assim, verifica-se que o termo "valor de mercado" foi adotado pelo Banco Central com uma interpretação bem abrangente, ao incluir parâmetros que na realidade se enquadrariam na definição de valor justo.

ludícibus e Martins (2007, p. 17) preconizam que a definição de valor justo seja alterada para algo mais objetivo. Segundo os autores, o valor justo seria "o valor de mercado, definido como o quanto se deveria desembolsar no mercado para que uma entidade adquirisse o ativo objeto de avaliação, aproximadamente no mesmo estado em que se encontra”.

\subsection{Transferência entre categorias}

A reavaliação quanto à classificação dos títulos somente pode ocorrer nas datas de balanço. Para os títulos da categoria mantidos até o vencimento, a venda ou transferência somente poderá ocorrer por um motivo isolado, não usual, não recorrente e não previsto, de modo a não descaracterizar a intenção evidenciada pela instituição quando da classificação original.

A restrição de venda foi atenuada com a edição da Resolução 3.181, do CMN, de 29 de março de 2004, que estabeleceu que a alienação dos títulos públicos federais

\begin{tabular}{|c|c|c|}
\hline Categorias & Contabilização & Impacto \\
\hline I - títulos para negociação & $\begin{array}{l}\text { Valor de mercado, com ajuste } \\
\text { reconhecido na conta de } \\
\text { resultado. }\end{array}$ & $\begin{array}{l}\text { - Maior volatilidade nos resultados, pois os ganhos e perdas } \\
\text { não realizados são reconhecidos no resultado. } \\
\text { - Permite a melhoria do lucro, para títulos com valor de } \\
\text { mercado superior ao custo. }\end{array}$ \\
\hline $\begin{array}{l}\text { II - títulos disponíveis para } \\
\text { venda }\end{array}$ & $\begin{array}{l}\text { Valor de mercado, com ajuste } \\
\text { reconhecido em conta destaca- } \\
\text { da do PL. }\end{array}$ & $\begin{array}{l}\text { - Maior volatilidade no PL, pois os ganhos e perdas não } \\
\text { realizados são reconhecidos no PL. }\end{array}$ \\
\hline $\begin{array}{l}\text { III - títulos mantidos até o } \\
\text { vencimento }\end{array}$ & $\begin{array}{l}\text { Custo de aquisição, sem ajuste } \\
\text { a valor de mercado. }\end{array}$ & $\begin{array}{l}\text { - Evita a volatilidade nos resultados e no patrimônio líquido. } \\
\text { - Prejudica a liquidez, pois não podem ser vendidos, para } \\
\text { atender uma eventual necessidade de liquidez. }\end{array}$ \\
\hline
\end{tabular}

Quadro 2 Impactos decorrentes da classificação dos TVMs 
classificados na categoria de mantidos até o vencimento, simultaneamente à aquisição de novos títulos da mesma natureza, com prazo de vencimento superior e em montante igual ou superior ao dos títulos alienados, não descaracterizam a intenção da instituição financeira quando da sua classificação na referida categoria. Dessa forma, essa norma abrandou as exigências anteriores, permitindo que houvesse a troca de títulos públicos federais classificados na categoria de mantidos até o vencimento.

\subsection{Exigências de divulgação}

A Circular 3.068/01 estabelece a obrigatoriedade de divulgação, em notas explicativas às demonstrações fi- nanceiras, de informações que abranjam, no mínimo, os seguintes aspectos relativos a cada categoria de classificação:

I o montante, a natureza e as faixas de vencimento;

Il os valores de custo e de mercado, segregados por tipo de título, bem como os parâmetros utilizados na determinação desses valores;

III o montante dos títulos reclassificados, o reflexo no resultado e os motivos que levaram à reclassificação;

IV os ganhos e as perdas não realizados no período, relativos a títulos e valores mobiliários classificados na categoria títulos disponíveis para a venda.

\section{PRINCIPAIS DIFERENÇAS}

Os pronunciamentos do FASB (SFAS 115), IASB (IAS 39) e do Banco Central (Circular 3.068/01), no tocante à contabilização dos títulos e valores mobiliários, são em sua maior parte semelhantes, embora algumas diferenças pontuais existam, conforme destacado no Quadro $3 \mathbf{0}$.

\section{CONCLUSÃO}

A pesquisa das regras de contabilização dos títulos e valores mobiliários, estabelecidas pelo Banco Central (Circular 3.068/01), em comparação com o pronunciamento SFAS 115, do FASB e IAS 39, do IASB, evidenciou que, de forma geral, essas normas estão em harmonia, embora algumas diferenças pontuais existam.

Pode-se notar que existe uma preocupação crescente da comunidade contábil brasileira, em adotar procedimentos

\begin{tabular}{|c|c|c|}
\hline FASB (SFAS 115) & IAS (IAS 39) & BACEN (Circular 3.068/01) \\
\hline $\begin{array}{l}\text { Escopo } \\
\text { Aplica-se a todas as entidades, contem- } \\
\text { plando somente a contabilização dos } \\
\text { títulos e valores mobiliários. }\end{array}$ & $\begin{array}{l}\text { Escopo } \\
\text { Aplica-se a todas as entidades e apresen- } \\
\text { ta-se como um pronunciamento de esco- } \\
\text { po abrangente, permitindo que qualquer } \\
\text { ativo ou passivo financeiro seja avaliado a } \\
\text { valor justo. }\end{array}$ & $\begin{array}{l}\text { Escopo } \\
\text { Aplica-se às instituições financeiras e } \\
\text { demais entidades autorizadas a funcio- } \\
\text { nar pelo Banco Central, contemplando } \\
\text { somente a contabilização dos títulos e } \\
\text { valores mobiliários. }\end{array}$ \\
\hline $\begin{array}{l}\text { Disponíveis para venda } \\
\text { Estabelece que os ganhos e perdas não } \\
\text { realizados dessa categoria devem ser } \\
\text { reportados como outros resultados abran- } \\
\text { gentes. }\end{array}$ & $\begin{array}{l}\text { Disponíveis para venda } \\
\text { Estabelece que os ganhos e perdas não } \\
\text { realizados dessa categoria devem ser } \\
\text { registrados como um componente sepa- } \\
\text { rado do patrimônio líquido. }\end{array}$ & $\begin{array}{l}\text { Disponíveis para venda } \\
\text { Semelhante ao IASB. }\end{array}$ \\
\hline $\begin{array}{l}\text { Mantidos até o vencimento } \\
\text { Estabelece que a venda ou transferência } \\
\text { de títulos dessa categoria devem ser } \\
\text { raras, podendo ocorrer somente em } \\
\text { situações específicas, definidas no pro- } \\
\text { nunciamento. }\end{array}$ & $\begin{array}{l}\text { Mantidos até o vencimento } \\
\text { Semelhante ao FASB. }\end{array}$ & $\begin{array}{l}\text { Mantidos até o vencimento } \\
\text { A Resolução 3.181/04 permitiu a alie- } \\
\text { nação de títulos públicos federais dessa } \\
\text { categoria, desde que de forma simul- } \\
\text { tânea ocorresse a aquisição de novos } \\
\text { títulos de mesma natureza, com prazo de } \\
\text { vencimento superior e em montante igual } \\
\text { ou superior ao dos títulos alienados. }\end{array}$ \\
\hline $\begin{array}{l}\text { Transferência entre categorias } \\
\text { Permite a reclassificação da e para a } \\
\text { categoria de negociação, que é similar } \\
\text { à categoria de valor justo, por via dos } \\
\text { resultados adotada pelo IASB. }\end{array}$ & $\begin{array}{l}\text { Transferência entre categorias } \\
\text { Proíbe a transferência da e para a catego- } \\
\text { ria de valor justo, por via dos resultados. }\end{array}$ & $\begin{array}{l}\text { Transferência entre categorias } \\
\text { Semelhante ao FASB. }\end{array}$ \\
\hline
\end{tabular}


que estejam em harmonia com as normas internacionais No âmbito das instituições financeiras, os comunicados BCB 14.259/06 e 16.669/08, determinaram a adoção de ações no sentido de promover a convergência das normas brasileiras às normas internacionais de Contabilidade. Para as sociedades anônimas abertas, a Instrução CVM 457/07 estabeleceu que as suas demonstrações financeiras deverão, a partir do exercício findo em 2010, adotar o padrão contábil internacional, de acordo com os pronunciamentos do IASB.

\section{Referências}

BANCO CENTRAL DO BRASIL. Circular 3.068, de 8 de novembro de 2001. Estabelece critérios para registro e avaliação contábil de títulos e valores mobiliários. Disponível em: <http://www.bcb.gov:br/?BUSCANORMA>. Acesso em: 16 mar. 2005.

Comunicado 14.259, de 10 de março de 2006. Comunica procedimentos para a convergência daś normas de contabilidade e auditoria. Disponível em: <http://www.bcb.gov.br/?BUSCANORMA>: Acesso em: 23 jun. 2008.

Comunicado 16.669, de 20 de março de 2008. Comunica procedimentos para a convergência das normas de contabilidade e auditoria. Disponível em: <http://www.bcb.gov.br/?BUSCANORMA >. Acesso em: 23 jun. 2008.

BASEL COMMITTEE ON BANK SUPERVISION. Report to G7 finance ministers and central bank governors on International Accounting Standards. Basel Committee Publications. Basel, 04/2000. Disponível em: <http://www.bis.org/publ/bcbs70.pdf >. Acesso em: 15 abr. 2005.

BRASIL. Lei 6.404, de 15 de dezembro de 1976. Dispõe sobre as sociedades por ações. Disponível em: < http://www.planalto.gov.br/ccivil_03/ Leis/principal_ano.htm>. Acesso em: 23 jun. 2008.

Lei 11.638, de 26 de dezembro de 2007. Altera e revoga dispositivos da Lei 6.404, de 15 de dezembro de 1976. Disponível em: <http:// www.planalto.gov.br/ccivil_03/Leis/principal_ano.htm>.Acesso em: 23 jun. 2008.

COMISSÃO DE VALORES MOBILIÁRIOS. Instrução CVM 457, de 13 de julho de 2007. Dispõe sobre a elaboraçấo e divulgação das demonstraçôes financeiras consolidadas, com base no padrão contábil internacional emitido pelo International Accounting Standards Board - IASB. Disponível em: < http://www.cvm.gov.br/>. Acesso em: 23 jun. 2008.

CONSELHO MONETÁRIO NACIONAL. Resolução 3.181, de 29 de março de 2004. Estabelece procedimentos para a alienação de títulos públicos federais classificados na categoria títulos mantidos até o vencimento. Disponível em: $<$ http://www.bcb.gov.br/?BUSCANORMA $>$. Acesso em: 23 mar. 2005.

FINANCIAL ACCOUNTING STANDARDS BOARD. SFAS 115 Accounting for Certain Investments in Debt and Equity Securities. 05/1993. Disponível em: <http://www.fasb.org/st/\#fas25>. Acesso em: 16 out. 2003.

SFAS 130 Reporting Comprehensive Income. 06/1997. Disponível em: <http://www.fasb.org/st/ \#fas25>. Acesso em: 17 mar. 2005.

SFAS 159 The Fair Value Option for Financial Assets and Financial Liabilities. 02/2007. Disponível em: <http://www.fasb.org/pdf/ aop_FAS159.pdf $>$. Acesso em: 04 abr. 2008.

FORAN, N. J.; FORAN, M. F. SFAS 12 and the conceptual framework. Accounting Horizons. Sarasota, v. 1, n. 4, p. 43-50, dez. 1987. Proquest ABI/Inform Global.

HENDRIKSEN, E. S.; VAN BREDA, M. F. Teoria da contabilidade. 1. ed. São Paulo: Atlas, 1999.

INTERNATIONAL ACCOUNTING STANDARDS BOARD. IAS 39 Financial Instruments: Recognition and Measurement, (Revised 2003).

Norma Internacional de Contabilidade - IAS 39 Instrumentos Financeiros: Reconhecimento e Mensuração (revisada em 2000). In: Normas Internacionais de Contabilidade 2001. São.Paulo: IBRACON, 2002.

IUDÍCIBUS, S.; MARTINS, E. Uma investigação e uma proposição sobre o conceito e o uso de valor justo. Revista de Contabilidade \& Finanças- Edição 30 anos de Doutorado. São Paulo. p. 9-18, jun. 2007.

JORDAN, C. E. et al. Earnings management under SFAS no. 115: Evidence from the insurance industry. Journal of Applied Business Research. Laramie, v. 14, n. 1, p. 49-57, winter 1997/1998. Proquest ABI/Inform Global.

LISBOA, L. P.; PIGATTO, J. A. M.; COSTA, F. M. Valor justo em contabilidade. In: CONGRESSO BRASILEIRO DE CONTABILIDADE, 16. 2000, Goiânia/GO. Anais... Goiânia: Conselho Regional de Contabilidade, 2000.

WAMPLER, B. M.; PHILLIPS JR., T. J. A case for fair value accounting for debt securities. Management Accounting. Montvale, v. 75, n. 9, p. 46-49, mar. 1994. Proquest ABI/Inform Global.

\section{NOTA - Endereço dos autores}

R. Itaipuru, 500 - apto. 43

São Paulo - SP

04143-010 